\title{
o conflito armado e os impactos na saúde dos trabalhadores que atuam na Estratégia de Saúde da Família na cidade do Rio de Janeiro
}

The armed conflict and the impacts on the health of workers acting in the Family Health Strategy in the city of Rio de Janeiro, RJ, Brazil

\author{
Raphael Sampaio dos Santos ${ }^{\mathrm{a}}$ \\ (iD) https://orcid.org/0000-0001-6250-4712 \\ E-mail: enfe.raphaelœgmail.com \\ Lucia Cardoso Mourão ${ }^{a}$ \\ (iD) https://orcid.org/0000-0002-7058-4908 \\ E-mail: luciamourao®hotmail.com \\ Ana Clementina Vieira de Almeida ${ }^{a}$ \\ (i) https://orcid.org/0000-0002-9342-6179 \\ E-mail: ana.vieiradealmeidaœgmail.com

\section{Katerine Moraes dos Santos ${ }^{b}$} \\ (iD) https://orcid.org/0000-0002-2064-5207 \\ E-mail: katerinegmळgmail.com

\section{Lutianni Dias Brazolino} \\ (D) https://orcid.org/0000-000I-9535-3754 \\ E-mail: lutianni.grsळgmail.com

\section{Isabel Cristina de Moura Leite} \\ (iD) https://orcid.org/0000-0003-4459-7606 \\ E-mail: isabelcristinademouraleite®gmail.com \\ aniversidade Federal Fluminense. Escola de Enfermagem Aurora \\ de Afonso Costa. Rio de Janeiro, RJ, Brasil. \\ bUniversidade Federal do Rio de Janeiro. Instituto de Atenção à \\ Saúde São Francisco de Assis. Escola de Enfermagem Anna Nery. \\ Rio de Janeiro, RJ, Brasil.
}

\section{Correspondência}

Raphael Sampaio dos Santos

Universidade Federal Fluminense, Escola de Enfermagem Aurora de Afonso Costa. Rua Dr. Celestino, 74, Centro. Niterói, RJ, Brasil. CEP 24020-091.

\section{Resumo}

Com ampliação da Estratégia Saúde da Família no Rio de Janeiro, equipes de saúde inseridas em territórios permeados por conflitos armados tornaram-se vulneráveis à violência urbana. 0 objetivo do trabalho foi analisar o afetamento que tais conflitos causam na saúde desses trabalhadores. Trata-se de uma pesquisa-intervenção, com abordagem qualitativa, realizada com 13 profissionais de saúde de nível superior em uma unidade de saúde da família localizada na cidade do Rio de Janeiro, utilizando como referencial teóricometodológico a análise institucional. Estresse, sentimentos de angústia, irritabilidade, pedidos de afastamento do trabalho, entre outros achados, emergem das falas dos participantes da pesquisa. Os conflitos armados são grandes tensionadores entre profissionais de saúde, usuários do serviço e gestão, fazendo emergir aspectos negativos, não só na saúde desses trabalhadores, como também em suas relações no serviço. Os riscos à integridade física e psíquica a que esses trabalhadores se submetem são constantes e têm impacto negativo profundo em sua saúde.

Palavras-chave: Conflitos Armados; Violência; Saúde do Trabalhador; Prática Profissional; Atenção Básica à Saúde. 


\section{Introdução}

With the expansion of the Family Health Strategy in Rio de Janeiro, RJ, Brazil, some health teams are inserted in territories permeated by armed conflicts becoming vulnerable to urban violence. The objective of the study was to analyze the effect these conflicts cause in the health of these workers. This is an intervention research, with qualitative approach, carried out with 13 health professionals in a family health unit located in the city of Rio de Janeiro, using institutional analysis as a theoretical-methodological referential. Stress, anguish, irritability, requests for leave of absence, among other findings, emerge from the speeches of the research participants. Armed conflicts are great tensors among health professionals, service users and management, making negative aspects to emerge, not only in the health of these workers, but also in their relations at work. The risks to physical and mental integrity that these workers undergo are constant and have a profound negative impact on their health.

Keywords: Armed conflicts; Violence; Worker's Health; Professional Practice; Primary Health Care.
A Estratégia de Saúde da Família (ESF) é um modelo de reorganização da assistência à saúde tradicional que transforma o processo do cuidar, centrando-se na família e considerando o contexto em que ela está inserida, de modo a propiciar uma melhor compreensão e intervenção no processo de saúde e doença pelas equipes de saúde (Oliveira; Pereira, 2013). A ESF, porta de entrada para muitos usuários no Sistema Único de Saúde (SUS), vem sendo ampliada no Rio de Janeiro, onde a cobertura passou de 32,3\%, em 2010, para 52\% em 2016 (Neves et al., 2018).

A Zona Oeste do município do Rio de Janeiro, onde se localiza o cenário deste estudo, foi priorizada pela Secretaria Municipal de Saúde para iniciar a reorganização dos serviços de saúde, principalmente a expansão da ESF (Jesus, 2013). Essa área destaca-se por ser umas das regiões com pior desenvolvimento econômico e social, marcada pela violência e longo período de desassistência (Nogueira; Marino; Ferreira, 2016). Nessa perspectiva, dados apontam ainda que a Zona Oeste do Rio de Janeiro é a região com menor Índice de Desenvolvimento Humano (IDH) do município, marcada por significativa desigualdade social e realidades contrastantes (Instituto Rio, 2013).

A ampliação da ESF faz com que algumas equipes de saúde sejam alocadas em territórios com alto grau de vulnerabilidade social, ficando, consequentemente, expostas à violência urbana.

Esses territórios, onde é precária a presença do Estado, concentram desassistência, desemprego e pobreza, e sua população, vulnerável sob a perspectiva social, tem que lidar com a violência urbana em seu cotidiano, sendo o conflito armado uma das repercussões dessa violência. Esta, fenômeno evidente em territórios marcados pela pobreza, altera as rotinas das famílias e reflete nos vínculos dos serviços presentes nessas comunidades (Costa; Ferreira, 2017).

Corroborando essa afirmativa, estudo realizado em uma comunidade do Rio de Janeiro, que acompanhou o tratamento de indivíduos na atenção básica sob o contexto da violência urbana, foi afetado em decorrência do contexto social conturbado do cenário e teve o trabalho de campo retardado por meses por causa da violência armada (Ferreira; Engstron, 2017). 
Esse panorama reflete a necessidade de debater o tema da violência sob um ponto de vista complexo e intersetorial, que comtemple suas diversas perspectivas e leve em consideração os múltiplos setores envolvidos, tais como saúde, segurança e políticas públicas, tendo em vista que os vários aspectos que envolvem esse fenômeno impactam fortemente a saúde pública, seja pelo número de vítimas diretas, seja pelos agravos mentais e emocionais dos envolvidos, impactando negativamente na qualidade de vida dos indivíduos e coletividades (Cardoso et al., 2016).

Pelo exposto, observa-se que a violência urbana é um fenômeno de grande magnitude e sua discussão vem ganhando espaço no campo da saúde pública. Destaca-se neste estudo sua manifestação armada como fenômeno complexo que tem impactado o trabalho das equipes da ESF.

Como as equipes estão inseridas em territórios de maior vulnerabilidade social, consequentemente em permanente contato com suas manifestações, torna-se importante discutir sobretudo a violência em sua manifestação do conflito armado, no contexto da saúde dos trabalhadores que atuam na ESF, sob essas circunstâncias de trabalho, para melhor compreender esse fenômeno e intervir adequadamente em seus determinantes no processo de trabalho em saúde. Dessa forma, este estudo tem como objetivo analisar os impactos da violência, em sua manifestação do conflito armado, na saúde dos profissionais de nível superior da ESF.

Torna-se significativo salientar que um dos objetivos da pesquisa foi identificar o conteúdo sobre violência urbana abordado na formação de nível superior dos profissionais de saúde. Assim, ficaram fora do estudo profissionais de formação técnica e agentes comunitários de saúde, mesmo sendo conhecida sua proximidade com a violência urbana no território.

\section{Método}

Trata-se de um estudo exploratório com abordagem qualitativa, com desenho socioclínico institucional.

A análise institucional (AI) teve início na década de 1960, na França, difundindo-se no Brasil na década seguinte e tendo como referências para o institucionalismo francês os autores René Lourau,
Georges Lapassade e Félix Guattari, responsáveis pela constituição dos fundamentos da análise institucional e da socionálise. A “AI nasceu da articulação entre intervenção e pesquisa, entre teoria e prática" (L'Abbate, 2012, p. 197-198).

A análise institucional na vertente socioclínica institucional, proposta por Gilles Monceau, foi utilizada nesta pesquisa por ser considerada um método eficaz na construção de diálogos e invocação de reflexões e debates coletivos sobre a violência urbana e suas nuances em territórios violentos. A intervenção socioclínica foi realizada em dois encontros coordenados pelo pesquisador principal com auxílio dos pesquisadores orientadores da pesquisa, que contavam com experiência na condução de grupo socioclínico-institucional. Ressalta-se que se trata de uma intervenção com orientação institucionalista, pesquisa-intervenção que propõe a não separação sujeito/objeto, levando em conta as implicações do pesquisador e ressaltando sua não neutralidade na produção do conhecimento (Romagnoli, 2014).

Durante a intervenção socioclínica institucional, os pesquisadores e os participantes do estudo vivenciaram diferentes momentos, que podem ser traduzidos, na perspectiva da metodologia, nas características socioclínicas institucionais propostas por Monceau, que podem ser alcançadas no momento da intervenção socioclínica. Essas características são: a análise da encomenda e das demandas; a participação dos sujeitos nos dispositivos; o trabalho dos analisadores; a análise das transformações à medida que o trabalho avança; a aplicação de modalidades de restituição; o trabalho das implicações primárias e secundárias; a intenção da produção de conhecimentos; a atenção aos contextos e às interferências institucionais (Monceau, 2013).

Essa metodologia não está presa a protocolos, mas visa iniciar conexões com as questões sociais e, consequentemente, profissionais, permitindo uma relação entre os sujeitos da pesquisa e o objeto, a fim de se aproximar aqueles das situações vivenciadas pelos participantes, possibilitando assim compreender suas implicações e a dinâmica da instituição (Monceau, 2013).

Este estudo foi realizado em 2017 em uma Clínica da Família localizada na Zona Oeste do 
município do Rio de Janeiro a qual, à época, era constituída por sete equipes, todas desenvolvendo suas atividades em território violento. Cada equipe de saúde acompanhava em média de 3 mil a 4 mil usuários, sendo 19.987 o número total de usuários cadastrados na Clínica da Família à época.

Este artigo apresenta os resultados dos encontros socioclínicos institucionais, que ocorreram na sala de reunião da respectiva clínica da família no período da tarde, após a reunião de equipe. Integraram o estudo 13 profissionais de saúde de nível superior que exerciam suas atividades no local no momento da coleta de dados e se disponibilizaram a participar, sendo: sete enfermeiros, quatro médicos e dois dentistas das equipes de saúde da família da clínica.

Nesses encontros foi utilizado um roteiro para conduzir a discussão no coletivo sobre a temática estudada e os dados foram gravados por meio digital. O roteiro trazia para o grupo questões relacionadas ao processo de trabalho que os profissionais desenvolviam em meio a um território permeado por conflitos armados e questões relativas ao processo de formação. Dadas as dimensões deste texto vamos considerar os resultados obtidos no seguinte questionamento do roteiro: "Na opinião do grupo como é trabalhar em um local com episódios de violência armada?". Outras questões relacionadas a violência urbana em sua expressão dos conflitos armados não atendem ao escopo desta produção, porém não são consideradas menos importantes.

Obedeceu-se aos preceitos éticos da pesquisa com seres humanos, obtendo parecer favorável de Comitê de Ética e Pesquisa da instituição proponente e coparticipante no primeiro semestre de 2017.

\section{Resultados e discussão}

O conflito armado é uma realidade atual que vem se manifestando de forma frequente no estado do Rio de Janeiro e fazendo-se marcante em territórios vulneráveis (ocupados pela população mais pobre), onde é evidente a ineficiente atuação do Estado. Os estabelecimentos de saúde inseridos nesses territórios têm sofrido as consequências desses conflitos.

Conceitualmente, a violência relacionada ao trabalho é apontada como "toda ação voluntária de um indivíduo ou grupo contra outro indivíduo ou grupo que venha a causar danos físicos ou psicológicos, ocorrida no ambiente de trabalho, ou que envolva relações estabelecidas no trabalho ou atividades concernentes ao trabalho" (Oliveira; Nunes, 2008, p. 30). Estudo realizado com trabalhadores da ESF identificou que a violência sentida por eles é expressa pelo medo do risco de exposição, de ter a sua integridade ameaçada e de represálias (Lancman et al., 2009).

Esta pesquisa apresenta aspectos relativos ao trabalho de profissionais de saúde da ESF sob a ótica dos impactos à saúde desses sujeitos ao vivenciarem no cotidiano do trabalho a violência urbana em sua manifestação do conflito armado. A análise das falas dos participantes, emersas durante os encontros socioclínicos institucionais, permitiu observar a influência que os conflitos armados geram em sua saúde.

Nesse sentido, a partir dessas falas, serão analisados os riscos à integridade física e psíquica desses trabalhadores de saúde, cuja condição deflagra grandes inquietações em consequência dos tensionamentos gerados entre usuários, trabalhadores de saúde e gestão local, decorrentes de atravessamentos nas práticas desses profissionais. Tais tensionamentos são grandes geradores de estresse para esses trabalhadores de saúde, gerando riscos à integridade psíquica em muitos deles.

A ESF, por estar inserida em território com maior vulnerabilidade, está mais exposta à violência (Lancman et al., 2009) e os trabalhadores de saúde que desenvolvem suas atividades nesses locais, por vivenciarem constantemente as dinâmicas dos territórios, estão mais propícios a enfrentarem a violência urbana em suas diferentes facetas (Benicio; Barros, 2017).

Velloso et al. (2005) destacam que, de maneira geral, os profissionais têm uma sensação de maior proteção quando estão dentro das unidades de saúde, mas que essa segurança é abalada quando acontecem tiroteios, expondo a vulnerabilidade dessas pessoas diante dos confrontos externos à unidade. Podemos compreender por meio das falas a seguir, como esses trabalhadores de saúde, mesmo desenvolvendo suas atividades dentro das Clínicas da Família, estão sob risco à sua integridade física e psíquica: 
Todos os consultórios foram furados na verdade! Quando abriram consultório por consultório e viram as marcas de tiros, falaram: "Caraca, pega tiro aqui mesmo!”. (Paulão)

Teve um tiroteio aqui de confronto entre policiaise bandidos que começou a perfurar de bala a clínica inteira e todo mundo se jogando no chão [...]. Você vê como aconteceu naquele episódio ficou marca de bala, vidro quebrado, cortina arregaçada, tudo destruído nas salas. (Inácio)

A violência armada vitimou 44.861 pessoas no ano de 2014, apresentando um crescimento de 415,1\% desde o ano de 1980, mesmo considerando crescimento populacional de $65 \%$ nesse período, a mortalidade por armas de fogo é muito significativa e destaca-se por sua magnitude. Os homicídios são responsáveis por 95\% desse quantitativo, sendo as vítimas, em sua maioria, jovens, negros e do sexo masculino (Waiselfsz, 2016). Sua distribuição está relacionada às condições sociais de vida das populações e à falta de acesso às políticas sociais (Benicio; Barros, 2017).

A violência é tida como um obstáculo para o acesso da população aos serviços de saúde e, ao mesmo tempo, dos profissionais de saúde à comunidade, impedindo visitas domiciliares e influenciado na rotina dos serviços e no planejamento dos processos de trabalho (Benicio; Barros, 2017). Observa-se nas falas dos participantes que os riscos à integridade física do trabalhador da ESF são potencializados quando ele precisa exercer suas atividades fora da clínica, ficando mais vulnerável dentro do território. A fala a seguir retrata um momento em que uma participante é surpreendida durante uma visita domiciliar e se vê em meio a um conflito armado:

já teve dia de eu sair, quando eu ia entrar no território, a polícia entrou com caveirão. Deu tempo de entrar no barzinho, deitar no chão e esperar acalmar; e aí depois eu voltei pra unidade; às vezes é de repente. (Flor do Campo)

Além dos riscos à integridade física, Machado e Daher (2013) destacam que o enfrentamento de realidades adversas pelos profissionais de saúde que atuam em territórios perigosos é um fenômeno complexo, que traz problemas psicológicos pelo estresse constante, gerando exaustão emocional e prejuízo em diferentes áreas da vida pessoal e profissional, com acentuada diminuição da satisfação profissional no ambiente de trabalho. As falas a seguir retratam essa situação:

[Eu] estava sofrendo com esses tiroteios. (Wood).

$O$ indice de estresse e ansiedade dos profissionais que prestam assistência [...] isso éaltamente piorado pela violência urbana. A gente tá tentando doar aquilo que a gente não tem! A gente repassa às vezes ansiedade, a carga emocional que a gente recebe de um paciente para o outro. Porque a gente também vibra naquela [...] assim, vocêvê que às vezes o reflexo disso acontece até depois, quando o tiroteio não tá acontecendo naquele momento. [...] atender com barulho de tiro aqui nas costas da gente achando a qualquer hora iria varar a parede da clínica que é feito de material muito fino, muito frágil; eu pelo menos tinha contração nas costas quando eu ouvia um tiro achando que poderia entrar a qualquer hora. (Inácio)

A Organização Mundial de Saúde (WHO, 2008) adverte para a alta prevalência de riscos psicossociais a que estão expostos os trabalhadores da saúde na Europa, responsáveis pelo aumento de problemas como o estresse relacionado ao trabalho, violência, assédio e bullying no ambiente de trabalho. No que diz respeito à violência, pesquisa realizada em dois territórios vulneráveis do município do Rio de Janeiro identificou, na fala dos participantes, a violência urbana como um desafio permanente que interfere na gestão, no trabalho dos profissionais e no atendimento as usuários do sistema de saúde (Prata et al., 2017).

A mesma pesquisa refere processos de adoecimento de profissionais e pacientes, desencadeados pela violência cotidiana, destacando-se maior vulnerabilidade dos profissionais e relatos de episódios de tensão, estresse e até casos de sintomas psiquiátricos e surtos psicóticos. Afirmam os autores que "no relato das equipes, constatamos a centralidade da violência como fator de produção de adoecimentos e vulnerabilidades" (Prata et al., 2017, p. 47).

Podemos observar nos territórios cobertos por ESF que, por conta dos conflitos armados, não é incomum as 
unidades darem por encerradas suas atividades. Isso, na prática, torna-se um grande transtorno para os usuários, que perdem suas consultas agendadas. Tal situação é geradora de conflito entre usuários e trabalhadores de saúde, muitas vezes fonte de discussão e estresse. Frequentemente, a insistência dos usuários em manter a clínica aberta mesmo diante dos conflitos armados produz nos trabalhadores um sentimento de angústia por entenderem que isso seria banalizar os episódios de violência armada. A seguir, falas demonstram o exposto:

Paciente vem, está marcado há mais de um mês, dois meses marcado, chega no dia, dá tiro. É ruim para eles também [...] não tem mais espaço na agenda, tem que remarcar o paciente, tem que encaixar o paciente [...] complica muito nosso processo de trabalho. (Paulão)

Paciente acha que a gente trabalha na área de risco, a gente tem que estar acostumado com isso! (Flor do Campo)

Na verdade eu me aborreci também com o paciente, eu e o (referindo-se a um trabalhador da unidade) fechamos a porta principal; quando eu bati a porta, o paciente queria sair! Até um senhor de idade, ele falou "eu vou sair!", "por aqui o senhor não vai sair!", "o senhor dá a volta e sai por trás!" "não, eu vou sair por aqui!”. (Paulão)

Tem paciente que fica bravo quando a gente tem que fechar a unidade. (Amora)

As variadas manifestações de violência no processo de trabalho da enfermagem e dos demais profissionais de saúde têm repercussões em diferentes áreas, mas principalmente na saúde mental. À medida que os profissionais se sentem ameaçados em um ambiente de trabalho acometido pelos conflitos armados, os níveis de sofrimento psicológico se elevam. Essas repercussões vão além dos aspectos relacionados ao local de trabalho, já que os eventos danosos à saúde repercutem também na vida social e familiar do trabalhador, trazendo sentimentos de irritabilidade, crises de choro, angústia, tristeza, com implicações profundas para a saúde (Bordignon; Monteiro, 2016).

Nas falas abaixo podemos observar os desdobramentos da violência em sua manifestação armada no segmento familiar dos participantes da pesquisa, mostrando-se assim como grande causadora de tensionamentos.

\begin{abstract}
Afeta a saúde da nossa família, dos nossos parentes, você vê como é que afeta a saúde [...] a onda se propaga nas nossas relações. (Inácio)
\end{abstract}

Isso pesa realmente, a família fica cobrando! Fechou por conta de violência. [...] por que você não pede para sair de lá? (Pétala)

Estudo realizado no município de Belém (PA) com objetivo de analisar como a violência territorial impacta no processo de trabalho de enfermeiras que atuam na ESF mostrou que condições de trabalho precárias que colocam em risco a vida dos trabalhadores e a falta de oferta mínima de logística são consideradas violência ao trabalhador e repercutem negativamente não só na produção do trabalho, mas também na saúde dos profissionais (Polaro; Gonçalves; Alvarez, 2013). A fala a seguir aponta o sofrimento mental do profissional, causado pelo intenso tiroteio no território, e em seguida o comentário de como isso afeta sua produtividade no trabalho.

Estava sofrendo com esses tiroteios! Foram 40 minutos todo mundo deitado no chão, fiquei trancada com um bebê de cinco dias no meu banheiro, a mãe chorando [...]. E aí acaba e eles querem que a gente levante a poeira, a gente continue a atender, e não é assim! O psicológico fica afetado! O que eu acho pioré que às vezes começa o tiro e para, aívocêfica nervoso, você tem que voltar para o consultório continuar atendendo e fingir que está tudo bem! Só que não está, só que você tá nervoso. Demora um tempinho, até porque pelas coisas que a gente já passou aqui, a gente fica com medo de passar de novo. (Wood)

Gonçalves, Queiroz e Delgado (2017) referem que a violência urbana e suas dimensões são pouco debatidas no campo psicossocial, tornando-se necessário estar atento às importantes consequências do impacto da violência na saúde mental não só de usuários, mais também dos profissionais que atuam nesses serviços.

A falta da discussão sobre a temática nos espaços dos serviços e de acolhimento e manejo da gestão 
para o exposto parece ser motivo de sofrimento para esses trabalhadores, que cuidam da saúde, mas não se sentem cuidados. Desconsiderar as peculiaridades territoriais e não cuidar da saúde mental dos trabalhadores reflete negativamente no processo do cuidado dessas equipes em relação à comunidade, já que eles podem solicitar demissão, transferência, ou até mesmo ser afastados por licença para tratamento de saúde, em virtude dos impactos em sua saúde mental, descontinuando a assistência. Os depoimentos a seguir corroboram tal afirmativa:

Então assim, a gente tem que cuidar do outro mas ninguém dá nenhum tipo de apoio psicológico para a saúde mental, para a gente que está aqui, então às vezes a gente cuida sem ter condição de cuidar. [...] A questão não é nem só essa! A questão é assim: a gente está cuidando das pessoas, mas muitos de nós, tanto que alguns de nós já saíram daqui, a [referindo-se a um trabalhador de saúde] que trabalhava aqui na equipe Alfa [nome fictício], ela fez uma síndrome do pânico, ela não consegue nem passarnessa rua por causa disso! [...] $O$ médico que era da equipe Beta [nome fictício] também pediu pra sair, a [referindo-se a um profissional de saúde] que era da equipe Gama [nome fictício] pediu pra sair. (Wood)

Eu e a médica daqui fomos juntas, ela não aguentou e pediu demissão! (Flor do campo)

Observa-se que as situações de violência promovem maior rotatividade dos profissionais, influenciando na descontinuidade dos processos de trabalho e quebrando o vínculo entre usuário e profissional (Benicio; Barros, 2017).

Apesar do exposto, ressalta-se que o trabalho não é essencialmente fonte de sofrimento, por meio dele os trabalhadores têm a possibilidade de construção da sua identidade e expressão da sua subjetividade. Esta resulta da interação do sujeito com as dimensões do contexto de trabalho relações sociais de trabalho, condições de trabalho e organização do trabalho -, constituindo-se em uma relação dinâmica, na qual a saúde no trabalho materializa-se na busca pela integridade física, psíquica e social (Ferreira; Mendes, 2003).
Nesse grupo de trabalhadores, as relações socioprofissionais atuam como mediadoras do sofrimento que enfrentam cotidianamente, com relatos de profissionais que, após serem transferidos, retornaram para a unidade, mesmo com a permanência dos episódios de violência, em virtude das relações estabelecidas.

A gente tem colega que passou por isso, saiu daqui da unidade e foi para [outra unidade] e falava: "Paulão". Tem colegas médicos que não se falam. Foi pedir ajuda para o colega e ele não ajuda. Ele mesmo falou: "por mais que tenha violência aí, eu prefiro ficar aî"[...] ele preferia muito mais o ambiente daqui mesmo com os tiros do que o ambiente em que os colegas lá nem se falavam. (Paulão)

sofria, mas não como aqui com essa questão da violência, só que assim, tinha profissional que não falava um com o outro, e assim, isso pesa né! A gente já trabalha em um lugar conflituoso, a gente precisa, às vezes, de um apoio, uma parceria de um colega, $e$ ter essa questão é difícil. Acho que pesa muito, tanto é que eu acabei voltando para cá. (Flor do Campo)

Essas relações constituem-se nesse contexto estratégias defensivas, conforme define Dejours (1994 apud Mendes, 2007, p. 38), "regras de conduta construídas e conduzidas por homens e mulheres, variam de acordo com as situações de trabalho e são marcadas pela sutileza, engenhosidade, diversidade e inventividade, fazendo com que os trabalhadores suportem o sofrimento sem adoecer". O risco apontado por Dejours é de que essas estratégias defensivas se tornem uma ideologia defensiva, deixando de ser estratégias para serem o próprio objetivo do trabalhador, acarretando o risco de alienação, ou seja, ao mesmo tempo que possibilitam a convivência com o sofrimento, levam à alienação das suas verdadeiras causas (Dejours, 1994 apud Mendes, 2007).

Pesquisa realizada no Sul do Brasil em conjuntura semelhante aponta que boas relações no trabalho contribuem para o bem-estar do trabalhador (Ferigollo; Fedosse; Santos Filha, 2016). A partir dela, pode-se inferir que trabalhar em território permeado por conflitos armados propiciou a esses profissionais o estabelecimento de uma identidade 
de grupo, fortalecendo suas relações pessoais, o que, nesse contexto, foi significativamente favorável para o enfrentamento das tensões provocadas pela violência armada no território.

\section{Considerações finais}

São notórios os riscos à integridade física e mental a que esses trabalhadores estão submetidos ao atuarem em territórios permeados por conflitos armados. 0 estresse constante causado pela violência urbana em sua manifestação armada desencadeia neles sentimentos de angústia, medo, irritabilidade e tristeza, produzindo exaustão mental e afetando diretamente sua satisfação no trabalho.

O território onde o cenário do estudo está inserido é permeado por constantes guerras entre traficantes e policiais, o que torna a violência urbana não só uma grande criadora de obstáculos às práticas das equipes de saúde da família, mas também geradora de grandes riscos à integridade física e psíquica dos trabalhadores que lá exercem suas atividades.

Investigar as dimensões e efeitos da violência urbana em sua manifestação do conflito armado tornase relevante pela possibilidade de revelar seus impactos na saúde dos trabalhadores de saúde que atuam em territórios violentos. Assim, torna-se necessário levar essa discussão para os espaços dos serviços e considerar intervir nos afetamentos que os conflitos armados causam na saúde mental e nos possíveis danos à integridade física desses profissionais.

Uma das estratégias para lidarmos com essa realidade seria oferecer serviços de apoio psicológico e acompanhamento aos trabalhadores que atuam em áreas violentas. Também é relevante discutir e aprimorar ferramentas já existentes, como o acesso mais seguro no enfrentamento da violência urbana, e buscar novas formas de produzir medidas protetivas a esses trabalhadores, envolvendo coletivamente profissionais, usuários, gestores e demais setores da sociedade.

\section{Referências}

BENICIO, L. F. S.; BARROS, J. P. P. Estratégia

Saúde da Família e violência urbana: abordagens e práticas sociais em questão. Sanare, Sobral, v. 16, n. 1, p. 102-112, 2017. Disponível em: <https://bit.ly/2IjWSvL>. Acesso em: 4 ago. 2018.

BORDIGNON, M.; MONTEIRO, M. I. Violence in the workplace in nursing: consequences overview. Revista Brasileira de Enfermagem, Brasília, v. 69, n. 5, p. 939-942, 2016. Disponível em: <https://bit.ly/2LKLMSN. Acesso em: 23 abr. 2017.

CARDOSO, F. L. M. G. et al. Homicídios no Rio de Janeiro, Brasil: uma análise da violência letal. Ciência \& Saúde Coletiva, Rio de Janeiro, v. 21, n. 4, p. 1277-1288, 2016. Disponível em: <https://bit.ly/20M749y>. Acesso em: 16 jul. 2018.

COSTA, S. L.; FERREIRA, R. S. Violência urbana e assistência social no âmbito da proteção social básica. Revista de Políticas Públicas e Segurança Social, Teófilo Otoni, v. 1, n. 1, p. 54-76, 2017. Disponível em: <https://bit.ly/2LI8FWT>. Acesso em: 3 mar. 2018.

FERIGOLLO, J. P.; FEDOSSE, E.; SANTOS FILHA, V. A. V. Qualidade de vida de profissionais da saúde pública. Cadernos Brasileiros de Terapia Ocupacional, São Carlos, v. 24, n. 3, p. 497-507, 2016. Disponível em: <https://bit.ly/32YJFR1>. Acesso em: 10 nov. 2018.

FERREIRA, J. T.; ENGSTRON, E. M. Estigma, medo e perigo: representações sociais de usuários e/ou traficantes de drogas acometidos por tuberculose e profissionais de saúde na atenção básica. Saúde e Sociedade, São Paulo, v. 26, n. 4, p. 1015-1025, 2017. Disponível em: <https://bit.ly/2IeTxOL>. Acesso em: 16 jul. 2018.

FERREIRA, M. C.; MENDES, A. M. Trabalho e riscos de adoecimento: o caso dos auditoresfiscais da Previdência Social Brasileira. Brasília, DF: Ler, Pensar, Agir, 2003.

GONÇALVES, H. C. B.; QUEIROZ, M. R.; DELGADO, P. G. G. Violência urbana e saúde mental: desafios de uma nova agenda? Fractal: Revista de Psicologia, Niterói, v. 29, n. 1, p. 17-23, 2017. Disponível em: $\langle$ https://bit.ly/32Xbp8E >. Acesso em: 3 maio 2018.

INSTITUTO RIO. Sobre a Zona Oeste. Rio de Janeiro, 2013. Disponível em: <https://bit.ly/3oESmi1>. Acesso em: 2 abr. 2017.

JESUS, R. V. L. A expansão da Estratégia Saúde da Família na cidade do Rio de Janeiro 2009-2012: estudo de caso na Área Programática 5·3. 2013. 
Dissertação (Mestrado em Saúde Pública) - Escola Nacional de Saúde Pública, Fundação Oswaldo Cruz, Rio de Janeiro, 2013. Disponível em: <https:// bit.ly/2OgdmJb>. Acesso em: 6 jul. 2018.

L'ABBATE, S. Análise institucional e intervenção: breve referência à gênese social e histórica de uma articulação e sua aplicação na saúde coletiva. Mnemosine, Rio de Janeiro, v. 8, n. 1, p. 194-219, 2012. Disponível em: <https://bit.ly/2MbKiNj>. Acesso em: 5 nov. 2015.

LANCMAN, S. et al. Repercussões da violência na saúde mental de trabalhadores do Programa Saúde da Família. Revista de Saúde Pública, São Paulo, v. 43, n. 4, p. 682-688, 2009. Disponível em: <https://bit.ly/2pIoogd>. Acesso em: 3 ago. 2018.

MACHADO, C. B.; DAHER, D. V. Violence in the area and its repercussions upon health care actions: descriptive-exploratory study. Online Brazilian Journal Nursing, Niterói, v. 12, p. 674-676, 2013. Disponível em: <https://bit. ly/2M9AdUj>. Acesso em: 27 mar. 2016.

MENDES, A. M. (Org.). Psicodinâmica do trabalho: teoria, método e pesquisas. São Paulo: Casa do Psicólogo, 2007.

MONCEAU, G. A socioclínica institucional para pesquisas em educação em saúde. In.: L'ABBATE, S.; MOURÃO, L. C.; PEZZATO, L. M. (Org.). Análise institucional \& saúde coletiva. São Paulo: Hucitec, 2013. p. 91-103.

NEVES, R. G. et al. Time trend of Family Health Strategy coverage in Brazil, its Regions and Federative Units, 2006-2016. Epidemiologia e Serviços de Saúde, Brasília, DF, v. 27, n. 3, p. 1-8, 2018. Disponível em: <https://bit.ly/396jFHh>. Acesso em: 22 dez. 2019.

NOGUEIRA, M. A.; MARINO, L. M. M. R.; FERREIRA, C. D. Investimento em atenção primária: uma revolução da saúde na Área Programática 5·3. Revista Saúde em Foco, Rio de Janeiro, v. 1, n. 2, 2016. Disponível em: <https://bit. ly/3oGYJ4f $>$. Acesso em: 18 jun. 2018.

OLIVEIRA, M. A. C.; PEREIRA, I. C. P. Atributos essenciais da atenção primária e a Estratégia Saúde da Família. Revista Brasileira de Enfermagem, Brasília, DF, v. 66, p. 158-164, 2013. Número especial. Disponível em: <https:// bit.ly/2nJ7mt4>. Acesso em: 25 mar. 2016.
OLIVEIRA, R. P.; NUNES, M. O. Violência relacionada ao trabalho: uma proposta conceitual. Saúde e Sociedade, São Paulo, v. 17, n. 4, p. 22-34, 2008. Disponível em: <https://bit. ly/2VckFDq >. Acesso em: 3 ago. 2018.

POLARO, S. H. I.; GONÇALVES, L. H. T.; ALVAREZ, A. M. Enfermeiras desafiando a violência no âmbito de atuação da Estratégia Saúde da Família. Texto \& Contexto Enfermagem, Florianópolis, v. 22, n. 4, p. 935-942, 2013. Disponível em: <https://bit. ly/331cpbT>. Acesso em: 5 jul. 2018.

PRATA, N. I. S. S. et al. Saúde mental e atenção básica: território, violência e o desafio das abordagens psicossociais. Trabalho, Educação e Saúde, Rio de Janeiro, v. 15, n. 1, p. 33-53, 2017. Disponível em: <https://bit.ly/30Krmoy>. Acesso em: 3 ago. 2018.

ROMAGNOLI, R. C. O conceito de implicação e a pesquisa-intervenção institucionalista. Psicologia \& Sociedade, Belo Horizonte, v. 26, n. 1, p. 44-52, 2014. Disponível em: <https://bit. ly/2IkcijA>. Acesso em: 23 abr. 2016.

VELLOSO, I. S. C. et al. A visão dos profissionais de saúde sobre a violência no cotidiano de trabalho em uma unidade básica. Reme: Revista Mineira de Enfermagem, Belo Horizonte, v. 9, n. 4, p. 302-o8, 2005. Disponível em: <https://bit. ly/2IfmXwb>. Acesso em: 17 mar. 2016.

WAISELFSZ, J. J. Mapa da violência 2016: homicídios por armas de fogo no Brasil. São Paulo: Flacso Brasil, 2016. Disponível em: <https://bit. ly/2NojWzK>. Acesso em: 4 ago. 2018.

WHO - WORLD HEALTH ORGANIZATION. PRIMA$\varepsilon F$ : guidance on the European Framework for Psychosocial Risk Management: a resource for employers and worker representatives. Genebra: World Health Organization, 2008. (Protecting Workers' Health Series n. 9).

\section{Contribuição dos autores}

Sampaio dos Santos, Mourão e Vieira de Almeida conceberam e delinearam o estudo e, com Moraes dos Santos, Brazolino e Moura Leite, analisaram $e$ interpretaram os dados, redigiram o artigo, procederam à revisão crítica e aprovaram a versão a ser publicada.

Recebido: 07/08/2019

Aprovado: 30/09/2019 